American Journal of Environmental Sciences 4 (4): 362-366, 2008

ISSN 1553-345X

(C) 2008 Science Publications

\title{
Chemical Contaminants and Toxicity of Ganga River Sediment from Up and Down Stream Area at Kanpur
}

\author{
K. R. Beg and S. Ali \\ Department of Chemistry, H. N. B. Garhwal University, P.O. Box 78, \\ Srinagar, Garhwal, Pin Code 246174, India
}

\begin{abstract}
The objective of this study was the sediment quality assessment of Ganga River at Kanpur city where effluents from tannery industries are discharged. Sediment samples from upstream and downstream area were collected and analyzed for trace metals and toxicity bioassay. Among various trace metals examined $\mathrm{Cr}$ in downstream sediment was 30-fold higher than in upstream sediment and its concentration was above the probable effect level. In general trace metals in the downstream sediment were found higher compared to reported earlier. Seed germination bioassay revealed negligible effect on the growth of root but the shoot growth was stunted in seeds exposed to downstream sediments. Trace metals determined in sediment elutriate showed poor elution of metals in aqueous phase but elutriates exerted toxic effects on both root and shoot growth, suggesting presence of other bioavailable toxic factor associated with sediment. The study revealed that seed germination bioassay may be used to differentiate contaminated and uncontaminated sediment.
\end{abstract}

Key words: Trace metals, ganga river sediment, seed germination bioassay

\section{INTRODUCTION}

The tannery industry mushrooming in North India has converted the Ganga River into a dumping ground. The tanning industry discharges different types of waste into the environment, primarily in the form of liquid effluents containing organic matters, chromium, sulphide ammonium and other salts. As per an estimate, about $80-90 \%$ of the tanneries use chromium as a tanning agent. Of this, the hides take up only $50-70 \%$, while the rest is discharged as effluent. Pollution becomes acute when tanneries are concentrated in clusters in small area like Kanpur. Consequently, the Leather-tanning sector is included in the Red category of industries due to the potential adverse environmental impact caused by tannery wastes. The Government of India (GOI) has numerous laws in place that affect the leather industry. Tanneries in India are required to comply with the regulations of the Central Pollution Control Boards and concerned State Pollution Control Boards. In 1996, the Supreme Court of India ordered the closure of all tanneries that had not set up pollution control systems. Using government subsidies, the tanneries have built numerous Common Effluent Treatment Plants (CETPs) to treat the toxic wastewater from tanneries. Despite this initiative, many of the pollution problems are still unresolved. The major components of the tannery effluents are the toxic trace metals ${ }^{[1]}$. Several analyses reveal high concentrations of chromium even in supposedly treated effluents. The majority of chemicals discharged into aquatic system eventually end up in sediments that may act as a sink of pollution as well as a source of pollution. Sediments are ecologically important components of the aquatic habitat which play a significant role in maintaining the trophic status of any water body ${ }^{[2]}$. Thus, study of sediment helps in the understanding of pollution effect as the residence time of pollutants in sediment of impacted area is long.

As reported earlier ${ }^{[3]}$, that highly polluted sediments are adversely affecting the ecological functioning of rivers due to heavy metal mobilization from urban areas into biosphere. Distribution of heavy metals in sediments of the river Ganga and its tributaries have been carried out by several workers ${ }^{[4-}$ 11]. Monitoring of Ganga River from Rishikesh to Varanasi indicated that Kannauj to Kanpur and Varanasi are the most polluted stretches of the river $\mathrm{Ganga}^{[12-13]}$. Analysis of upstream and down stream water and sediment revealed a 10-fold increase in chromium level in the sediment at down stream Jajmau area of Kanpur showing unchecked release of untreated tannery effluent ${ }^{[1]}$. The present study is, therefore, focused on the sediment quality assessment of samples

Corresponding Author: K.R. Beg, Department of Chemistry, H.N.B. Garhwal University, P.O. Box 78, Srinagar, Garhwal, Pin Code 246174, India 
collected from up and down stream of the Ganga River at Kanpur in order to find current status of pollutants discharged from the mushrooming tannery industries of the city and other sources. Chemical criteria provide a benchmark from which to evaluate the significance of contaminant concentration. The sediments from the two sampling areas were further evaluated for the release of trace metals in aqueous elutriates and their gross toxic effects using seed germination bioassay.

\section{MATERIALS AND METHODS}

The locations of sampling stations are shown in Fig. 1. Two sampling areas were selected; sampling area-1 was up stream at Bithoor village from where river Ganga enters towards Kanpur City and sampling area-2 was down stream at Jajmau which is situated at the exit point of river Ganga from Kanpur city area. The sediment samples were collected from six stations covering around $1 \mathrm{~km}$ stretch at each station using grab sampler, kept in clean glass jars and transported to the laboratory in the cold box. The samples were stored in the freezer till analysis.

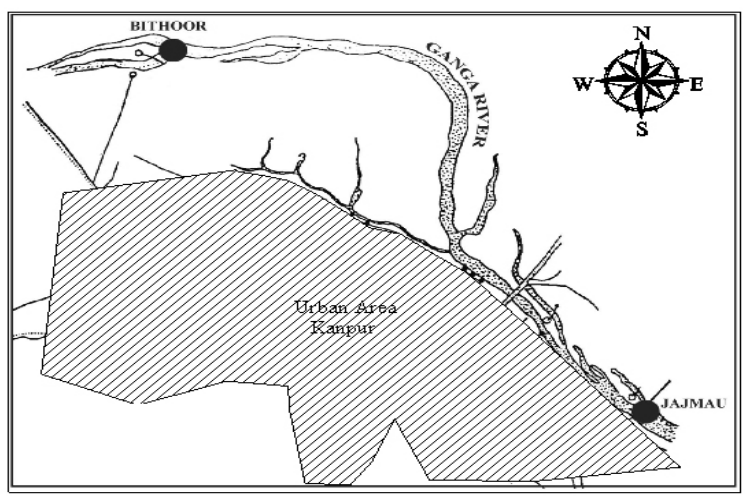

Fig. 1: Map showing location of sampling area in Ganga River at Kanpur
Trace metals (As, $\mathrm{Cd}, \mathrm{Cr}, \mathrm{Cu}, \mathrm{Fe}, \mathrm{Mn}, \mathrm{Ni}, \mathrm{Pb}, \mathrm{V}$ and $\mathrm{Zn}$ ) in the sediment were determined by digesting 1 g sediment sample with concentrated $\mathrm{HNO}_{3}$, made up to $50 \mathrm{ml}$ volume and analyzed by the atomic absorption spectrometer. Sediment elutriates were prepared by shaking sediment in water at 1:4 ratio for $24 \mathrm{~h}$. The supernatant was separated by centrifuging at $6,000 \mathrm{rpm}$ for $60 \mathrm{~min}$ at $4{ }^{\circ} \mathrm{C}$. Elutriate was stored at $4{ }^{\circ} \mathrm{C}$ until analysis ${ }^{[14]}$. Elutriate were acidified and directly used for the estimation of trace metals by atomic absorption spectrophotometer.

\section{RESULTS AND DISCUSSION}

The quality of water and sediment in the river system is seriously affected by pollutants which enter through drains that bring domestic as well as industrial effluents. These industrial and domestic waste waters, besides other pollutants also contain high concentration of heavy metals. Because of adsorption, hydrolysis and co-precipitation only a small portion of free metal ions stay dissolved in water and a large quantity of them get deposited in the sediment. The sediment from Bithoor and Jajmau area of Kanpur segment of Ganga river were analyzed for ten selected metals (As, $\mathrm{Cd}, \mathrm{Cr}, \mathrm{Cu}$, $\mathrm{Fe}, \mathrm{Mn}, \mathrm{Ni}, \mathrm{Pb}, \mathrm{V}$ and $\mathrm{Zn}$ ), their average concentration and the range are given in Table 1. In general, trace metal levels in sediment collected from down stream Jajmau area were higher than up stream area.

The increase in concentration ranged from 1.5- to 2-fold for most of the metals with the exception of As and $\mathrm{Pb}$ which showed no change and $\mathrm{Cr}$ which showed a dramatic increase in concentration in sediment from down stream area. The accumulation of $\mathrm{Cr}$ in sediment at Jajmau area was 30-fold higher than in sediment from upstream Bithoor area.

Table 1: Trace metals in upstream and downstream sediment and sediment elutriate of Ganga river at Kanpur segment

\begin{tabular}{|c|c|c|c|c|}
\hline \multirow{2}{*}{$\begin{array}{l}\text { Trace } \\
\text { Metals }\end{array}$} & \multicolumn{2}{|c|}{ Sediment $\left(\mathrm{mg} \mathrm{kg}^{-1}\right)$} & \multicolumn{2}{|c|}{ Sediment elutriate (ppm) } \\
\hline & Upstream & Downstream & Upstream & Downstream \\
\hline As & $0.25(0.25-0.25)$ & $0.25(0.25-0.25)$ & $0.02(0.02-.02)$ & $0.02(0.02-0.02)$ \\
\hline $\mathrm{Cd}$ & $3.66(2.5-6.0)$ & $2.50(2.5-2.5)$ & $0.20(0.2-0.2)$ & $0.20(0.2-0.2)$ \\
\hline $\mathrm{Cr}$ & $5.00(5.0-5.0)$ & $147(105-250)$ & $0.20(0.2-0.2)$ & $0.20(0.2-0.2)$ \\
\hline $\mathrm{Cu}$ & $8.83(7.0-10.0)$ & $16.8(15.0-17.0)$ & $0.20(0.2-0.2)$ & $0.20(0.2-0.2)$ \\
\hline $\mathrm{Fe}$ & $4600(39504950)$ & $7033(5900-8400)$ & $0.28(0.2-0.44)$ & $0.22(0.2-0.24)$ \\
\hline Mn & $110(85-125)$ & $187(160-254)$ & $0.43(0.2-0.8)$ & $0.26(0.2-0.4)$ \\
\hline $\mathrm{Ni}$ & $6.505 .0-7.5)$ & $10.3(8.5-13.0)$ & $0.20(0.2-0.2)$ & $0.32(0.2-0.56)$ \\
\hline $\mathrm{Pb}$ & $2.50(2.5-2.5)$ & $2.50(2.5-2.5)$ & $0.20(0.2-0.2)$ & $0.200 .2-0.2)$ \\
\hline V & $2.50(2.5-2.5)$ & $3.83(3.0-5.0)$ & $0.20(0.2-0.2)$ & $0.20(0.2-0.2)$ \\
\hline $\mathrm{Zn}$ & $36.33(23-44.5)$ & $61.7(55-70)$ & $0.46(0.2-1.0)$ & $0.77(0.8-1.0)$ \\
\hline
\end{tabular}


This suggests that sediment contamination is worsened in the last five years as earlier reported ${ }^{[1]}$, only 10-fold increase in $\mathrm{Cr}$ in sediment from similar areas of sampling.

Trace metals determined in the present study were in the bulk sediment and by comparing the present study results with the average of Indian River System (IRS) ${ }^{[5],}$ all the trace metals were found less in sediment samples from the upstream area Bithoor except $\mathrm{Zn}$. Whereas, in sediment from downstream sampling area Jajmau $\mathrm{Cr}, \mathrm{Cu}$ and $\mathrm{Zn}$ were high, among these metals $\mathrm{Cr}$ was extremely high. Same was the scenario when compared with the World River System (WRS). All the values of the present study were on the lower side compared with WRS values except $\mathrm{Cr}^{[15]}$, which also suggests that $\mathrm{Cr}$ pollution was very high at down stream area Jajmau due to discharges from tannery wastes.

The comparison of trace metal values obtained in the present study with IRS or WRS suggests that the condition of the Ganga River sediment was in general not alarming, but there are hot spots of contamination like downstream area Jajmau where pollutants accumulated due to the point source discharges from tannery industries. However, the dimension of the impacted area was not determined in this study. Comparison with freshwater sediment quality guidelines provide criteria for the evaluation of trace metal concentration in river sediments in response to adverse affects on the river's biological components. The levels of various trace metals obtained in the present study are compared with the lowest effect level (LEL) and probable effect level (PEL) and presented in (Table 2). In the LEL, sediments are considered to be clean to marginally polluted, where as no effects on the majority of sediment-dwelling organisms are expected below this concentration ${ }^{[16]}$. The PEL represents the level above which adverse effects to aquatic biota are

Table 2: Comparative study of Trace metals concentration $(\mathrm{mg} / \mathrm{kg})$ in sediment of up and downstream with lowest effect level (LEL) and probable effect level (PEL).

\begin{tabular}{lllll}
\hline $\begin{array}{l}\text { Trace } \\
\text { metals }\end{array}$ & LEL* & PEL** & Upstream & Downstream \\
\hline $\mathrm{As}$ & - & - & 0.25 & 0.25 \\
$\mathrm{Cd}$ & 0.6 & 3.53 & 3.66 & 2.5 \\
$\mathrm{Cr}$ & 26 & 90 & 5.0 & 147 \\
$\mathrm{Cu}$ & 16 & 197 & 8.8 & 16.8 \\
$\mathrm{Fe}$ & - & - & 4600 & 7033 \\
$\mathrm{Mn}$ & - & - & 110 & 187 \\
$\mathrm{Ni}$ & 16 & 36 & 6.5 & 10.3 \\
$\mathrm{~Pb}$ & 31 & 91.3 & 2.5 & 2.5 \\
$\mathrm{~V}$ & - & - & 2.5 & 3.8 \\
$\mathrm{Zn}$ & 120 & 315 & 36.3 & 61.7 \\
\hline
\end{tabular}

*LEL Lowest effect level (Persaud et al. 1993);

**PEL Probable effect level (Smith et al. 1996) predicted to occur frequently ${ }^{[17]}$. Using above criteria in the present study, $\mathrm{Cr}$ was the only trace metal above the PEL and LEL concentrations; whereas $\mathrm{Cu}$ is identified only above the LEL concentration.

Both metals may cause or contribute sediment toxicity to the freshwater ecosystem of the Ganga River. Future investigations should focus on the potential bioaccumulation of $\mathrm{Cr}$ and $\mathrm{Cu}$ in aquatic organisms and associated hazards that consume aquatic organisms.

Another question that was addressed in this study was the elutriation of trace metals from contaminated sediment samples that may shed light on their bioavailability. Vigorous physical and chemical methods of contaminant extraction appear to have the ability to remove contaminants from locations or binding sites that would normally be unaccessed under natural conditions. Sediment elutriation that relies on more natural method was adopted in this study as an accurate means of estimating risk to the aquatic environment. Sediment elutriates were also analyzed for the ten selected metals (As, $\mathrm{Cd}, \mathrm{Cr}, \mathrm{Cu}, \mathrm{Fe}, \mathrm{Mn}, \mathrm{Ni}$, $\mathrm{Pb}, \mathrm{V}$ and $\mathrm{Zn}$ ) as analyzed in the sediment samples and the data are given in Table 1.

Trace metal analysis of sediment elutriates showed that the concentrations of trace metals eluted were extremely low, as incorporation of metals in sediment limit their bioavailability but several studies linked sediment metal contamination to detrimental effect on benthic invertebrates of soft bottom communities ${ }^{[18-20]}$.

In order to study gross toxicity of sediment seed germination bioassay was conducted with the sediment samples from upstream and downstream areas. Exposure of seeds to sediment reduced the viability of seeds to 62.5 and $66 \%$ in up and downstream sediments respectively as compared to $100 \%$ viability observed in control soil. Germination of viable seeds in the sediment showed negligible effect on the growth of root but shoot growth was stunted in seeds exposed to downstream sediments. It was interesting to note that exposure of seeds to elutriate of downstream sediment samples inhibited both root and shoot growth (Fig. 2). A decrease of lower magnitude was also occurred in the growth of roots germinated in elutriates from upstream sediment samples whereas shoot growth was not influenced. Since toxic trace metals were poorly eluted and their concentration was very low, the inhibitory effect on the germination of seeds and specially the shoot growth may be attributed to other chemical contaminants possibly present in the sediment. It has been shown in the earlier studies that Ganga soil from the same area sampling was done in the present study sediment contained pesticide contamination and the 

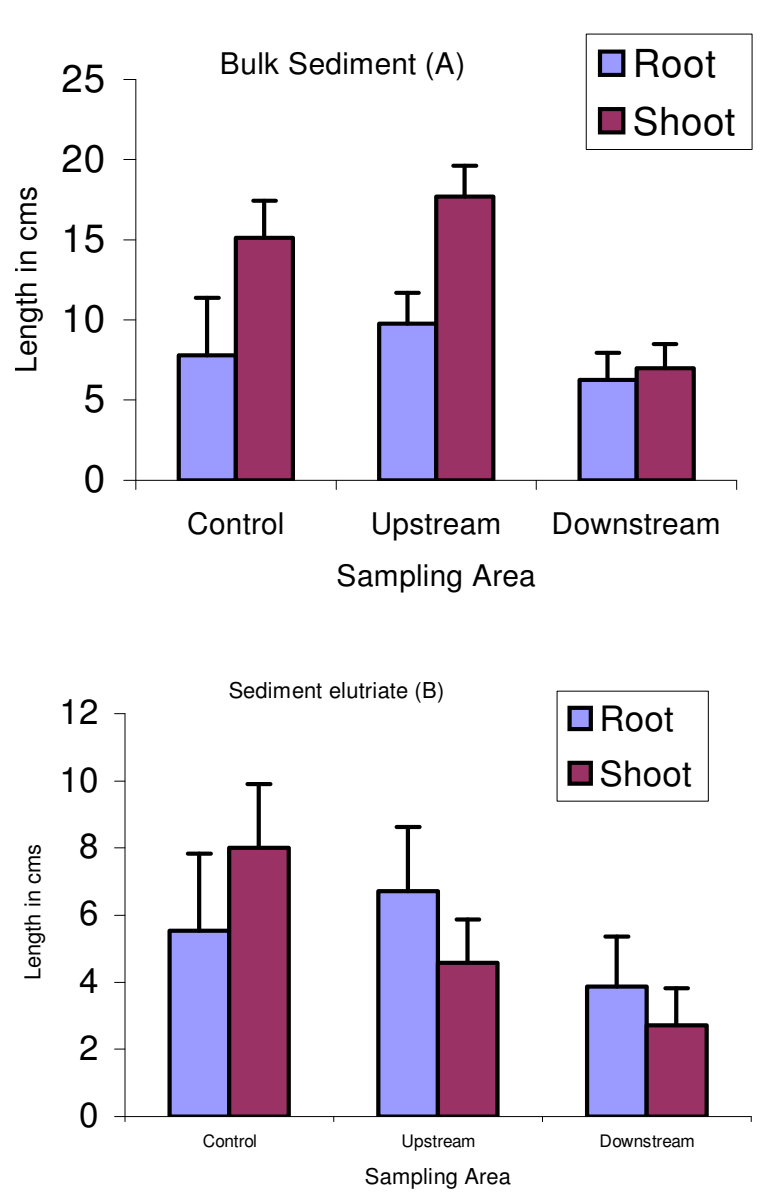

Fig. 2: Seed germination bioassay of bulk sediment (A) and in sediment elutriate (B) $\mathrm{m}$

crops grown on the Ganga soil accumulated higher concentration of pesticides ${ }^{[21]}$. Bioaccumulation of trace metals in the seedlings was not done in this study; however, risk of the accumulation of some toxic metals especially $\mathrm{Cr}$ is possible if any crop is grown in dried basins near the study area as reported earlier.

\section{CONCLUSION}

The present study revealed that the Ganga River gets seriously polluted by the discharges from tannery industries clustered on the bank of river in Kanpur. The sediment load with trace metals in the down stream area has been increased as compared to that reported 5 years back. Though trace metals from contaminated down stream sediment were not eluted in water in appreciable concentrations, but an inhibitory effect on seed germination was observed. This indicated presence of growth inhibitory pollutants in the sediment other than trace metals. Further studies are needed on the analysis of sediment for other priority pollutants and monitoring the area of influence in Ganga River at Kanpur segment.

\section{REFERENCES}

1. Khwaja A.R., R. Singh and S.N. Tandon, 2001. Monitoring of Ganga water and sediments vis-à-vis tannery pollution at Kanpur (India): A case study, Environ. Moni Assess, 68 (1): 19-35.

2. Singh, M., A.A. Ansari, G. Muller and I.B. Singh, 1997. Heavy metals in freshly deposited sediments of Gomti river (a tributary of the Ganga river): Effects of human activities Environ. Geol. 29 (3/4): 246-252.

3. Singh, M., G. Muller. and I.B. Singh, 2002. Heavy metals in freshly deposited stream sediments of rivers associated with urbanization of the Ganga plain, India. Water Air Soil Pollut. 141: 35-54.

4. Ajmal, M., M.A. Khan and A.A. Nomani, 1983 Pollution in the river Ganges (India). Water Sci. Technol. 16: 347-358.

5. Subramania, V., R. Van Grieken and L. Vant Dack, 1987. Heavy metal distribution in the sediments of Ganga and Brahmaputra Rivers. Environ. Geol. Water Sci. 9: 93-103.

6. Saikia, D.K., R.P. Mathur and S.K. Srivastava, 1988. Heavy metals in water and sediments of upper Ganga. Indian J. Environ. Health. 31(1): 11-17.

7. Jha, P.K., V. Subramanian, R. Sitasawad. and R. Van Grieken, 1990. Heavy metals in water and sediments of the Yamuna river (a tributary of the Ganga). Sci Total Environ. 95: 7-27.

8. Ansari, A.A., I.B. Singh and H.J. Tobschall, 2000. Importance of geomorphology and sedimentation process for metal dispersion in sediments and soils of the Ganga plain: Identification of geochemical domains, Chem Geol. 162: 245-266.

9. Datta, D.K and V. Subramanian, 1998. Distribution and fraction of heavy metals in the surface sediments of the Ganges-Brahmaputra-Meghana river system in the Bengal besin. Environ. Geol, 36: 93-101.

10. Ramesh R., A.L. Ramanathan, S. Ramesh, R. Purvaja and V. Subramanian, 2000. Distribution of rare earth elements in the surficial sediments of the Himalaya river system. Geochem. J., 34: 295-319. 
11. Singh, M., 2001. Heavy metal pollution in freshly deposited sediments of the Yamuna river (the Ganga river tributary): A case study from Delhi and Agra urban centres, India Environ. Geol. 40: 664-671.

12. Singh, M., G. Muller and I.B. Singh, 2003. Geogenic distribution and baseline concentration of heavy metals in sediments of the Ganges River. India J. Geochem. Explor. 80: 1-17.

13. Tare, V., A.V.S. Yadav and P. Bose, 2003. Analysis of photosynthetic activity in the most polluted strech of river Ganga. Water Res, 37: 67-77.

14. Munawar, M., D. Gregor, S.A. Daniels, W.P. Norwood, 1989. A sensitive screening bioassay technique for the toxicological assessment of small quanties of contaminated bottom or suspended sediment. Hydrobiologia, 176/177: 497-507.

15. Martin, J.M. and M. Meybeck, 1979. Elemental mass balance of materials carried by major world rivers. Mar. Chem.7: 173-206.

16. Persaud D., R. Jaagumani and A. Hayton, 1993. Guidelines for the protection and management of aquatic sediment quality in Ontario, Water resources branch, Ontario ministry of the environment, Toronto, pp: 27.
17. Smith, S.L., D.D. MacDonald, K.A. Keenleyside, C.G. Ingersoll and J. Field, 1996. A preliminary evaluation of sediment quality assessment values for freshwater ecosystem. J. Great Lakes Res, 22: 624-638.

18. Schlekhat, C.E., B.L. Megee, D.M. Boward, E. Reiharz and D.J. Velinsky and T.L. Wade, 1994. Tidal river sediments in the Washington D.C. area. Biological effects associated with sediment contamination. Estuaries, 17: 334-344.

19. Burton, G.A. and C. MacPherson, 1995. Sediment Toxicity Testing Issues and Methods. In: Handbook of Ecotoxicology, Eds hoffman, D.J. B.A. Rattner, G.A. Burton and J. Cairns, Lewis Publisher, Boca Raton, pp: 70-103.

20. Bastidas, C., D. Bone and E.M. Garcia, 1999. Sedimentation rates and metal content of sediments in a Venezuelan coral reef, Marine. Pollution. Bulletin. 38: 16-24.

21. Hans, R.K., M. Farooq, G. Suresh Babu, S.P. Srivastava, P.C. Joshi and P.N. Viswanathan, 1999. Agricultural produce in the dry bed of the River Ganga in Kanpur, India-A new source of pesticide contamination in human diets. Food and Chem. Toxicology. 37: 847-852. 